\title{
Supporting Information: Gas-phase Dissociation Chemistry of Deprotonated RGD
}

\author{
Shanshan Guan+,\|, Jordan M. Rabus',\|, Philippe Maîtreł, Benjamin J. Bythell ${ }^{\dagger}, \|^{*}$
}

†Department of Chemistry and Biochemistry, Ohio University, 391 Clippinger Laboratories, Athens, OH 45701

"Department of Chemistry and Biochemistry, University of Missouri-St. Louis, 1 University Blvd, St. Louis, MO 63121

'Laboratoire de Chimie Physique (UMR8000), CNRS, Univ. Paris-Sud, Université Paris-Saclay, 91405, Orsay, France

\section{AUTHOR INFORMATION}

Corresponding Author

*Benjamin J. Bythell, bythell@ohio.edu 
Table S1. Selected [RGD-H] $]^{-}$minima and transition structures. Relative energy values are generated from B3LYP/6-311++G(d,p) optimized structures and frequency calculations: $\Delta \mathrm{H}_{298 \mathrm{~K}}$ (B3LYP/6-311++G(d,p)), $\quad \Delta \mathrm{E}_{\mathrm{el}}\left(\mathrm{B} 3 \mathrm{LYP} / 6-311++\mathrm{G}(3 \mathrm{df}, 3 \mathrm{pd})\right.$ single point), $\Delta \mathrm{E}_{\text {el }}(\mathrm{M} 06-2 \mathrm{X} / 6-$ $311++\mathrm{G}(3 \mathrm{df}, 3 \mathrm{pd})$ single point), and $\Delta \mathrm{E}_{\mathrm{el}}$ (wB97XD/6-311++G(3df,3pd) single point).

\begin{tabular}{|c|c|c|c|c|c|c|c|}
\hline & \multicolumn{4}{|c|}{$\begin{array}{c}\text { B3LYP/ } \\
6-311++G(d, p)\end{array}$} & \multirow{2}{*}{$\begin{array}{c}\text { B3LYP/ } \\
6-311++\mathrm{G}(3 \mathrm{df}, 3 \mathrm{pd}) \\
\Delta E_{\mathrm{el}} / \\
\mathrm{kJ} \mathrm{mol}^{-1}\end{array}$} & \multirow{2}{*}{$\begin{array}{c}\mathrm{M} 06-2 \mathrm{X} / \\
6-311++\mathrm{G}(3 \mathrm{df}, 3 \mathrm{pd}) \\
\Delta E_{\mathrm{el}} / \\
\mathrm{kJ} \mathrm{mol}^{-1}\end{array}$} & \multirow{2}{*}{$\begin{array}{c}\text { wB97XD/ } \\
6-311++\mathrm{G}(3 \mathrm{df}, 3 \mathrm{pd}) \\
\Delta E_{\mathrm{el}} / \\
\mathrm{kJ} \mathrm{mol}^{-1}\end{array}$} \\
\hline & $E_{\mathrm{el}} / \mathrm{H}$ & $\begin{array}{l}\Delta H_{298 \mathrm{~K} /} \\
\mathrm{kJ} \mathrm{mol}^{-1}\end{array}$ & $\begin{array}{l}\Delta G_{298 \mathrm{~K} /} \\
\mathrm{kJ} \mathrm{mol}^{-1}\end{array}$ & $\begin{array}{c}\Delta S_{298 \mathrm{~K} /} / \\
\mathrm{J} \mathrm{K}^{-1} \\
\mathrm{~mol}^{-1}\end{array}$ & & & \\
\hline I_a & -1250.362823 & 0 & 0 & 0 & 0 & 17.6 & 13.7 \\
\hline I_b & -1250.360757 & 6.0 & 7.9 & -6.1 & 4.5 & 9.7 & 7.8 \\
\hline II & -1250.361306 & 4.2 & 4.3 & -0.1 & 3.6 & 21.4 & 16.8 \\
\hline III & -1250.357439 & 9.5 & 15.6 & -20.6 & 11.3 & 9.1 & 12.2 \\
\hline IV_a & -1250.358645 & 10.4 & 9.1 & 4.4 & 8.9 & 21.2 & 20.1 \\
\hline IV_b & -1250.357831 & 11.6 & 19.2 & -25.7 & 9.9 & 0 & 0 \\
\hline V & -1250.357682 & 13.0 & 10.4 & 8.6 & 11.7 & 22.9 & 22.9 \\
\hline VI & -1250.357046 & 16.1 & 17.5 & -4.9 & 14.4 & 16.9 & 16.8 \\
\hline VII & -1250.353927 & 25.1 & 37.9 & -42.8 & 26.3 & 18.4 & 16.8 \\
\hline VIII & -1250.351844 & 28.8 & 24.2 & 15.7 & 28.9 & 47.0 & 42.1 \\
\hline IX & -1250.325174 & 67.0 & 51.0 & 53.6 & 66.1 & 75.5 & 100.8 \\
\hline $\mathrm{X}$ & -1250.325464 & 71.4 & 51.4 & 66.9 & 68.9 & 84.2 & 108.2 \\
\hline TS_Anhydride & -1250.291753 & 181.6 & 180.9 & 2.5 & 163.0 & 184.1 & 198.8 \\
\hline $\mathrm{TS} \_\mathrm{b}_{2}+\mathrm{H}_{2} \mathrm{O}$ & -1250.305120 & 146.3 & 146.0 & 0.9 & 124.5 & 152.2 & 172.4 \\
\hline TS_c $c_{2}$ & -1250.272192 & 224.5 & 219.1 & 18.1 & 212.7 & 268.7 & 287.6 \\
\hline TS_H'trans_a & -1250.258142 & 256.5 & 256.9 & -1.2 & 245.8 & 272.8 & 290.8 \\
\hline $\mathrm{TS} \_\mathrm{Z}_{1} \_\mathrm{a}$ & -1250.274356 & 223.6 & 216.4 & 24.1 & 199.9 & 243.7 & 266.8 \\
\hline TS_H $\mathrm{H}^{+}$trans_b & -1250.259039 & 256.8 & 253.6 & 10.7 & 242.4 & 265.4 & 283.6 \\
\hline TS_z $Z_{1} \_b$ & -1250.280322 & 208.6 & 204.0 & 15.5 & 185.6 & 228.9 & 255.9 \\
\hline TS_H'transfer_c & -1250.244573 & 292.5 & 300.7 & -27.5 & 282.0 & 298.6 & 310.8 \\
\hline $\mathrm{TS} \_\mathrm{z}_{1 \_\mathrm{c}}$ & -1250.289247 & 186.8 & 191.2 & -15.0 & 164.2 & 194.0 & 214.1 \\
\hline TS_ZZ1_d & -1250.240266 & 299.5 & 296.2 & 11.3 & 296.8 & 351.0 & 362.4 \\
\hline
\end{tabular}




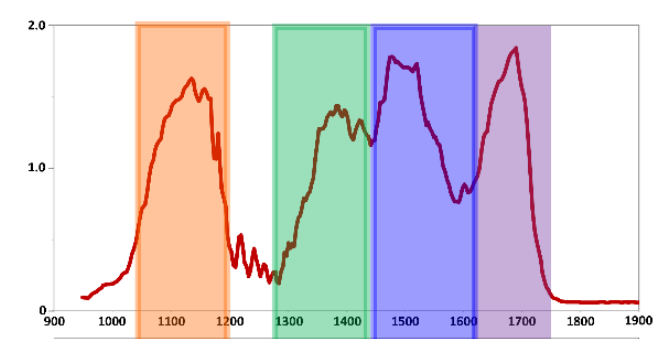

\section{[RGD-H] \\ anion}
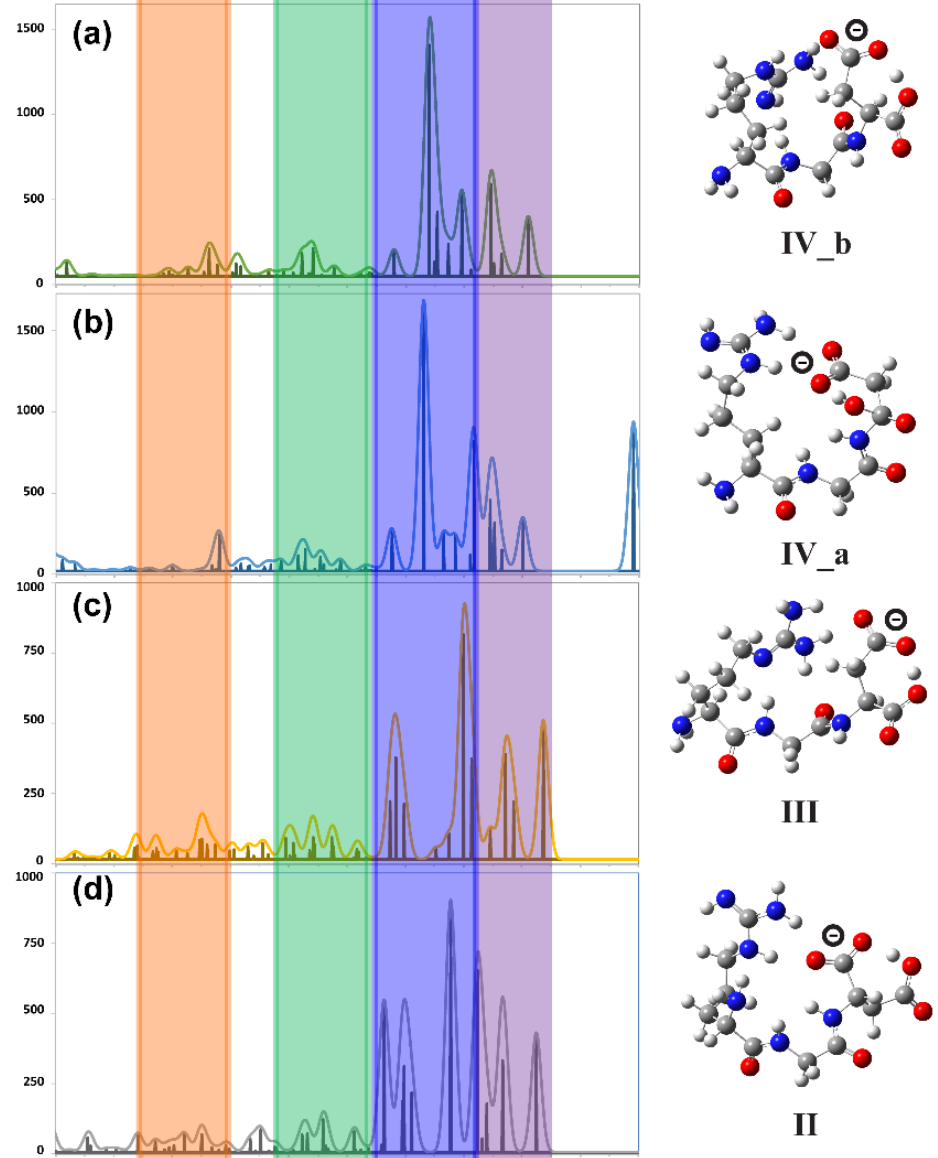

II
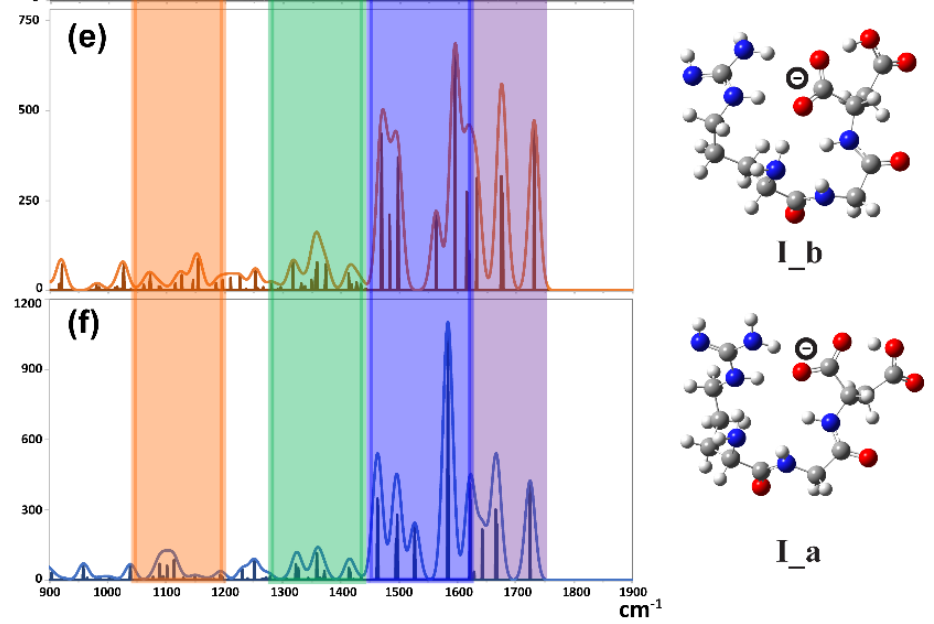

Figure S1. IRMPD action spectroscopy spectrum of [RGD-H]-compared to the lowest energy optimized structures obtained with B3LYP/6-311++G(d,p) calculations. Areas of potential overlap between theory and experiment are highlighted. 


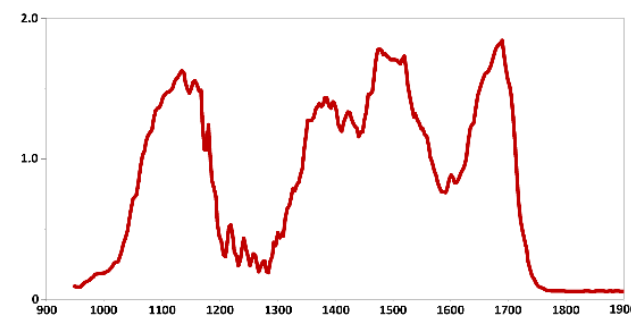

[RGD-H] anion
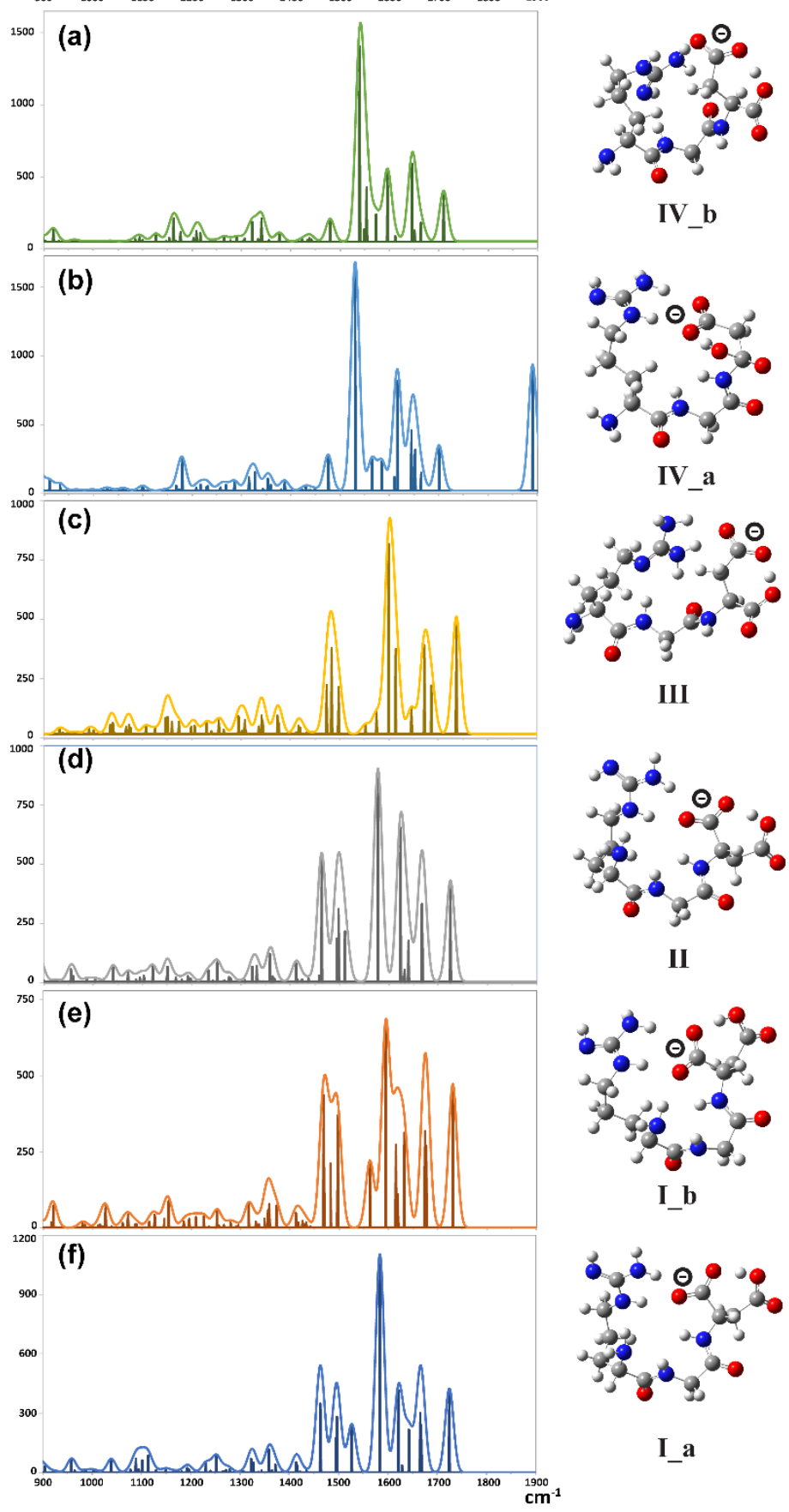

Figure S2. IRMPD action spectroscopy spectrum of [RGD-H]-compared to the lowest energy optimized structures obtained with B3LYP/6-311++G(d,p) calculations. 


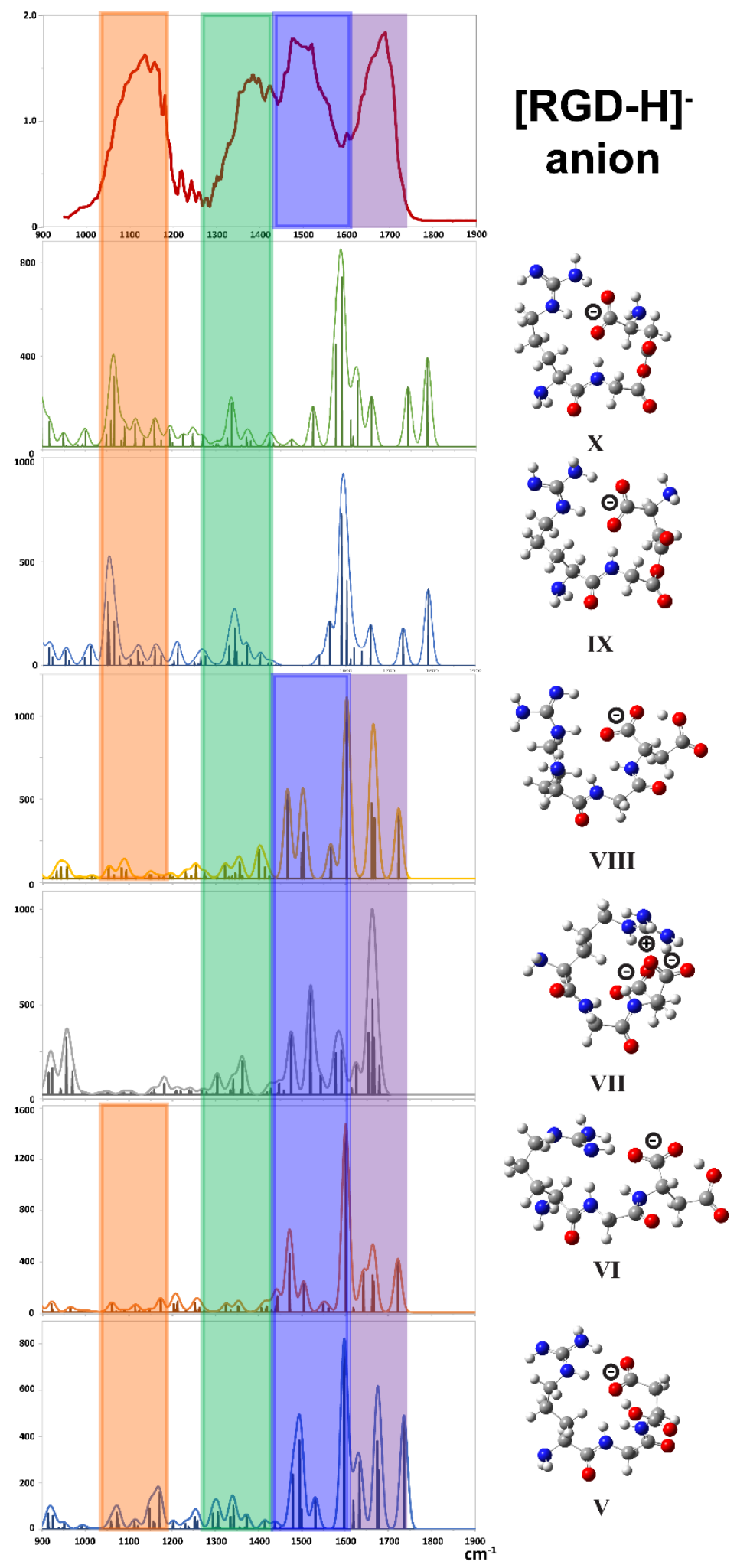

Figure S3. IRMPD action spectroscopy spectrum of [RGD-H] - compared to the low energy optimized minima (V-IIIV) and higher energy anhydride structures obtained with B3LYP/6-311++G(d,p) calculations. Areas of potential overlap between theory and experiment are highlighted. 


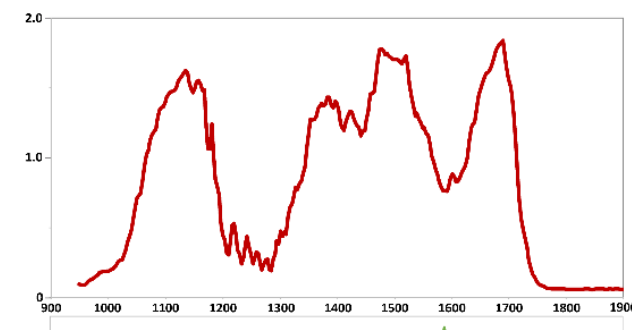

[RGD-H] anion
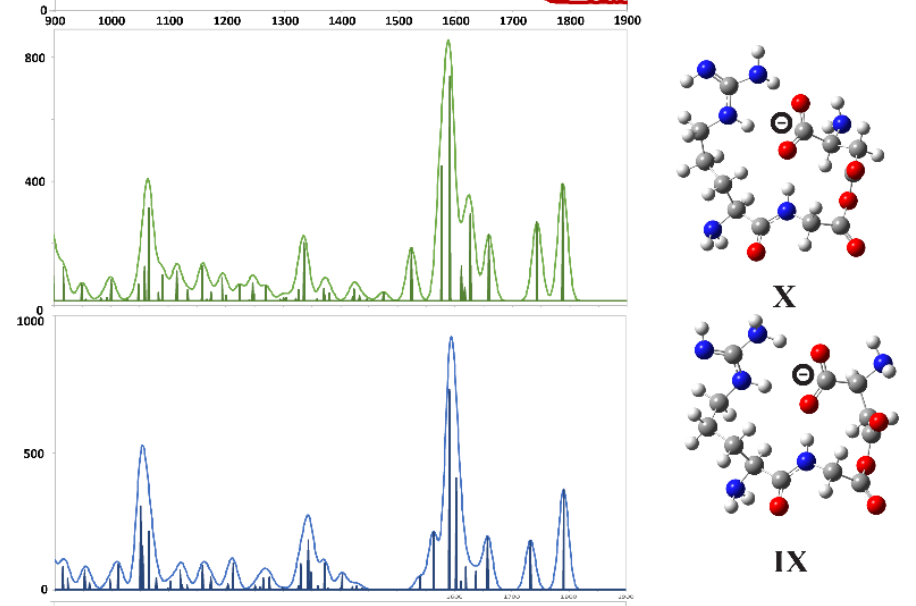

IX
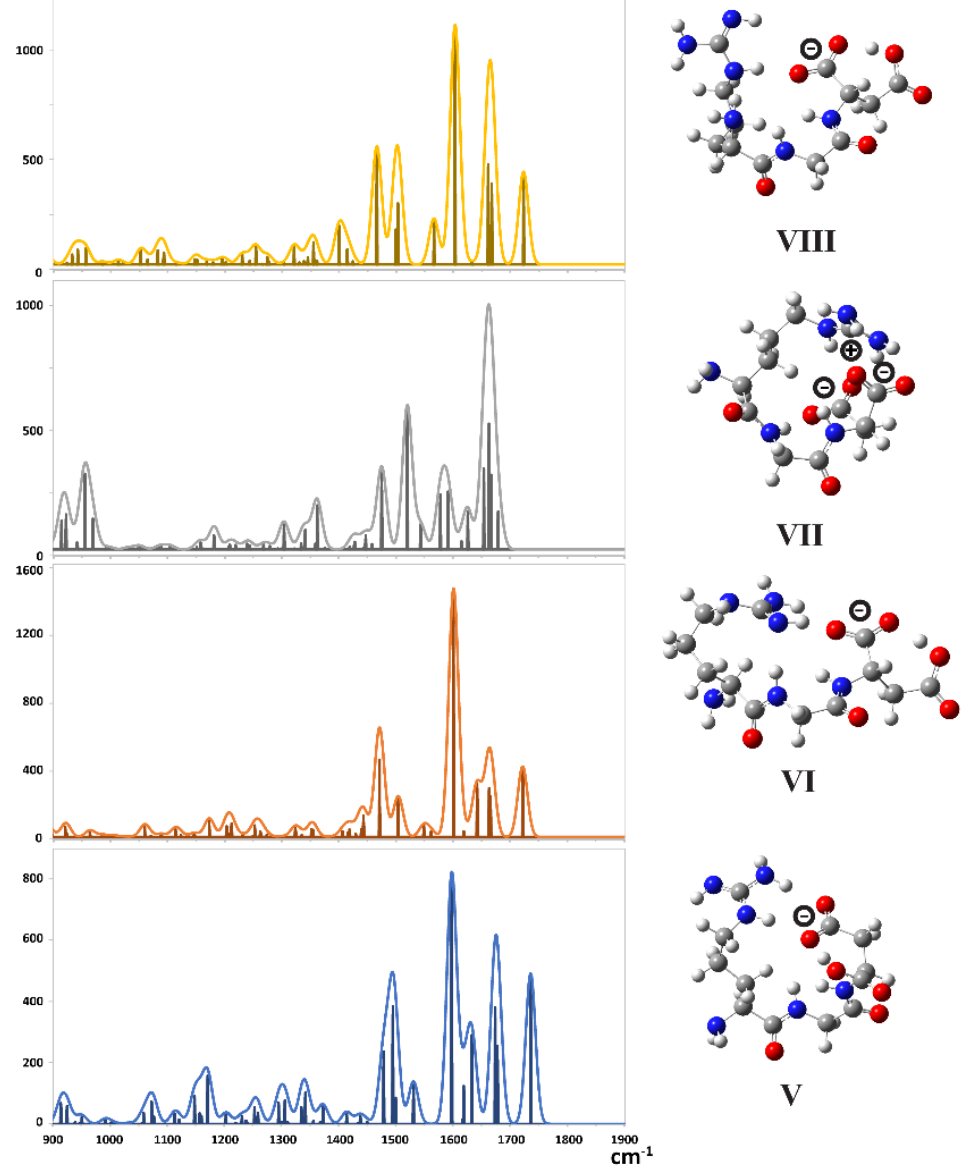

Figure S4. IRMPD action spectroscopy spectrum of [RGD-H]- compared to the low energy optimized minima (V-IIIV) and higher energy anhydride structures obtained with B3LYP/6-311++G(d,p) calculations. 

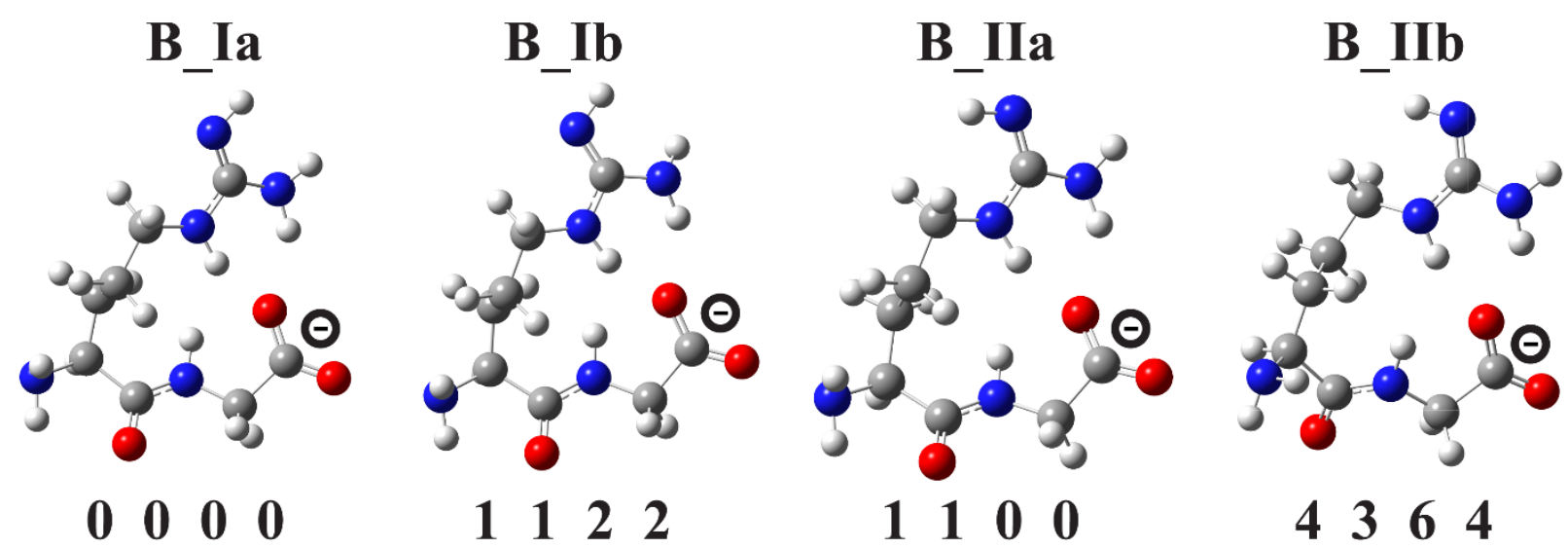

$\begin{array}{llllllllll}0 & 0 & 0 & 0\end{array}$

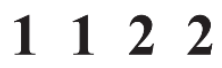

1100

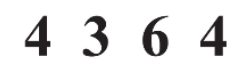

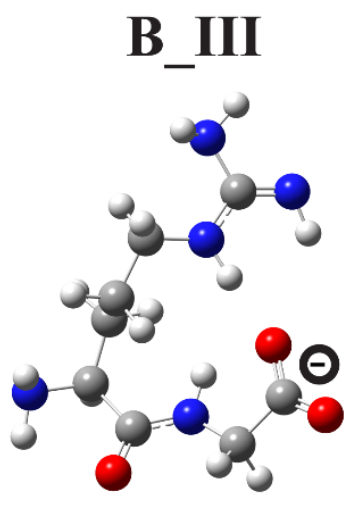

30303231

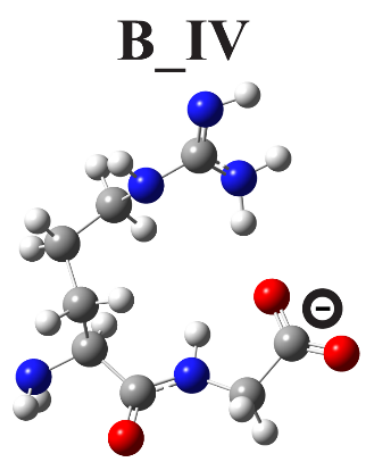

24243632

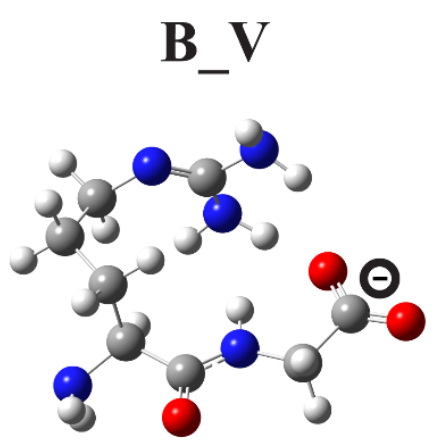

13141212

Figure S5: Selected low energy structures of putative $\mathrm{b}_{2}+\mathrm{H}_{2} \mathrm{O}$ anions. The four relative energy values are generated from B3LYP/6-311++G(d,p) optimized structures: $\Delta H_{298 \mathrm{~K}}$ $(\mathrm{B} 3 \mathrm{LYP} / 6-311++\mathrm{G}(\mathrm{d}, \mathrm{p})), \quad \Delta E_{\mathrm{el}}$ (B3LYP/6-311++G(3df,3pd) single point), $\Delta E_{\mathrm{el}} \quad(\mathrm{M} 06-$ $2 \mathrm{X} / 6-311++\mathrm{G}(3 \mathrm{df}, 3 \mathrm{pd})$ single point), and $\Delta E_{\mathrm{el}}$ (wB97XD/6-311++G(3df,3pd) single point). Approximate positions of the charges in each structure are provided for illustration. 


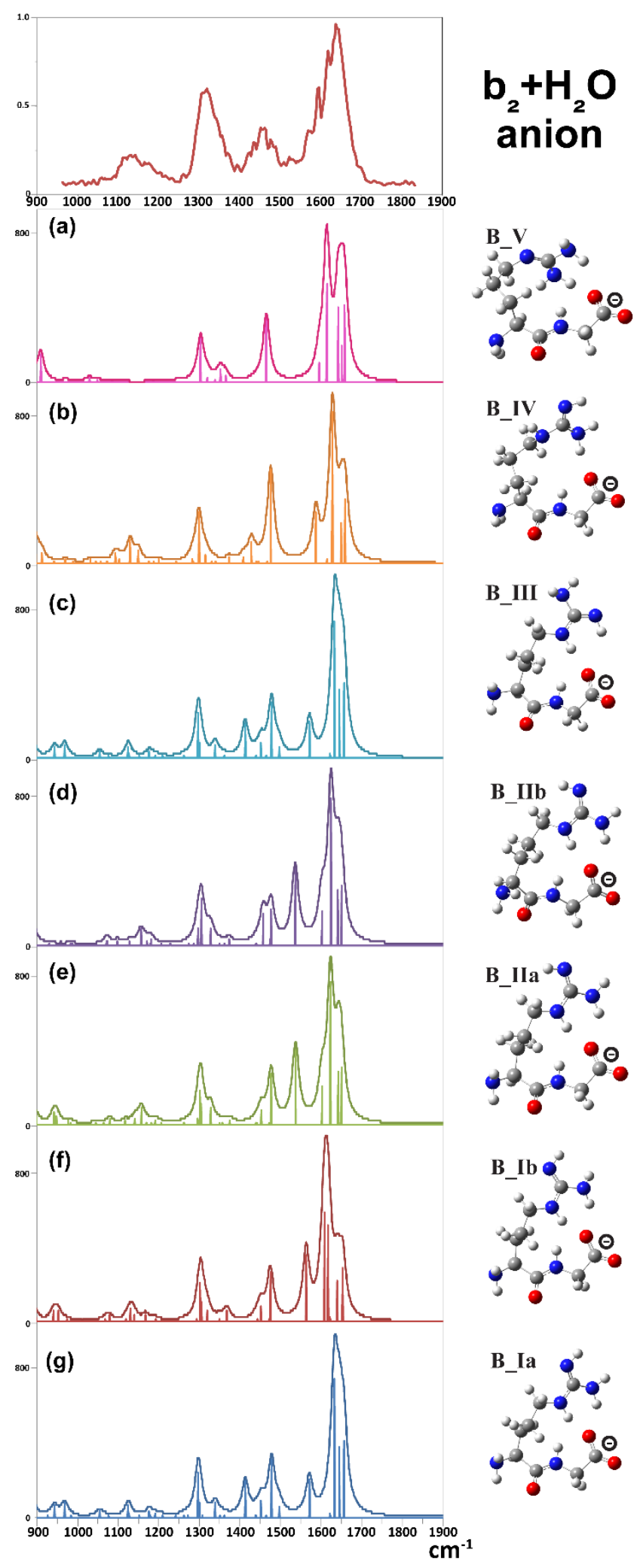

Figure S6. IRMPD action spectroscopy spectrum of $b_{2}+\mathrm{H}_{2} \mathrm{O}$ compared to the lowest energy optimized structures obtained with B3LYP/6-311++G(d,p) calculations. 


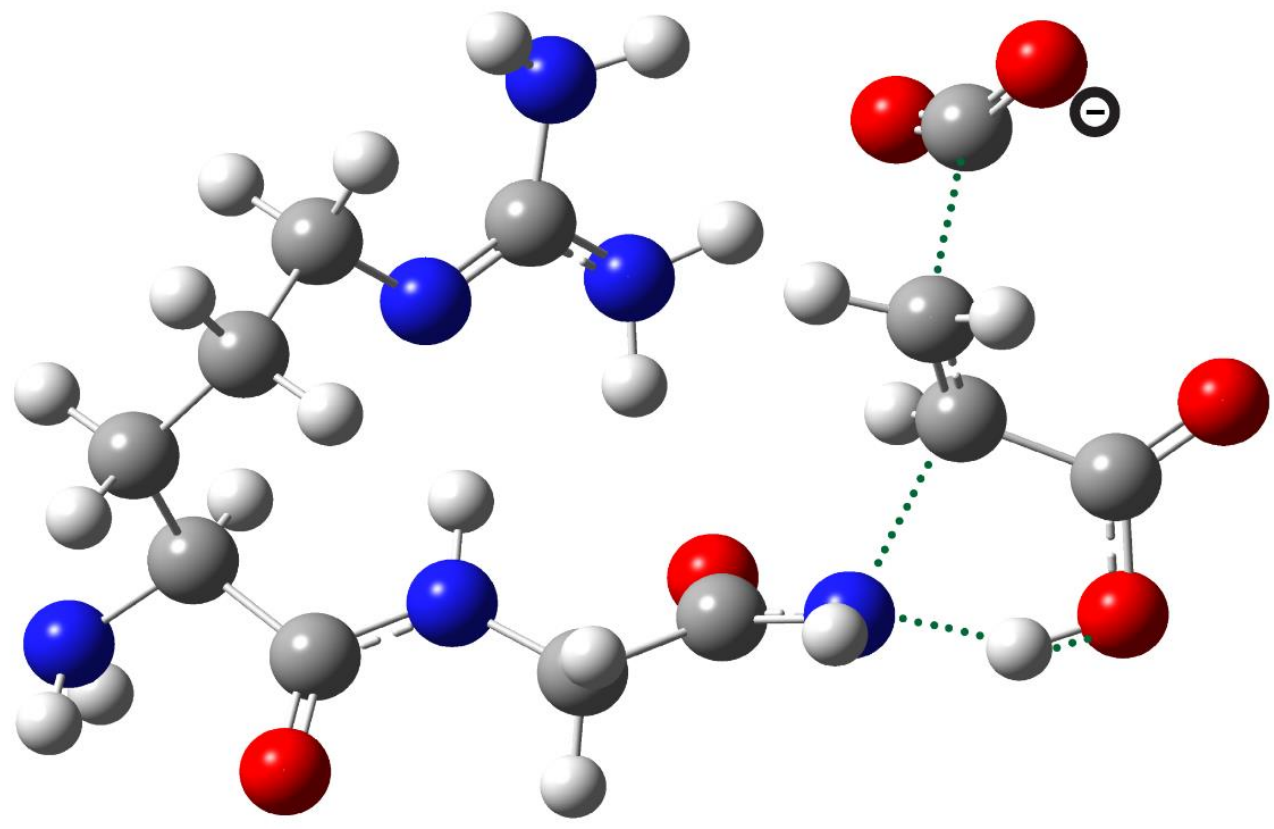

Figure S7: Lowest energy transition structure for formation of the $c_{2}$ anion, TS_c $c_{2}$. Approximate positions of the charges in each structure are provided for illustration. Green dotted lines indicate bonds being broken or formed. 
a)

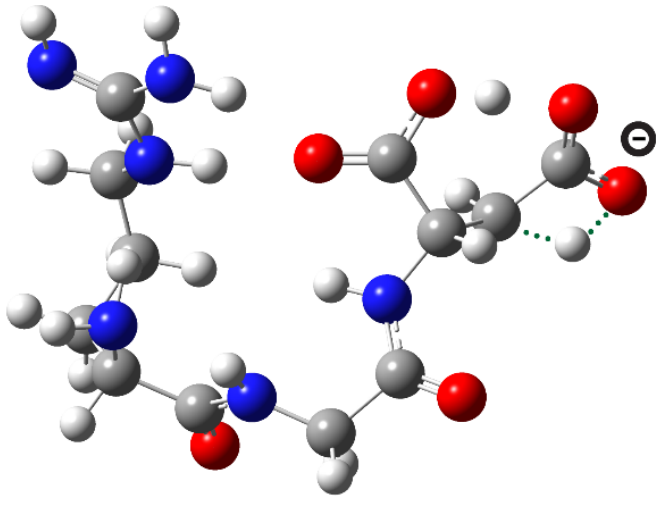

TS_H+trans_a

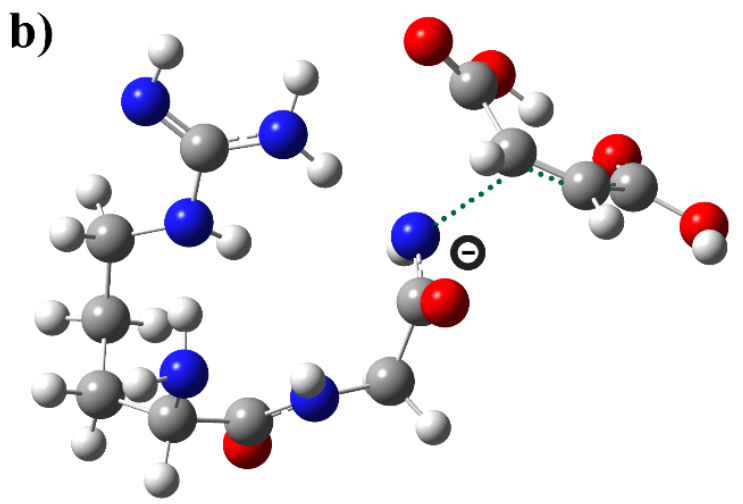

TS_z $\mathbf{z}_{1-} \mathbf{a}$ c)

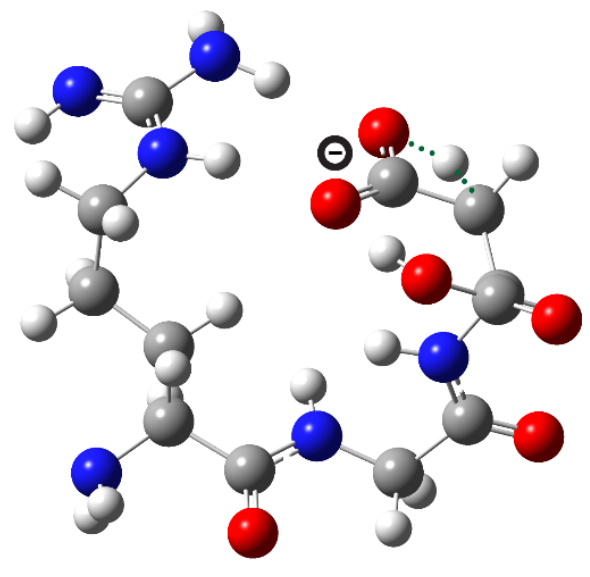

TS_H+trans_b d)

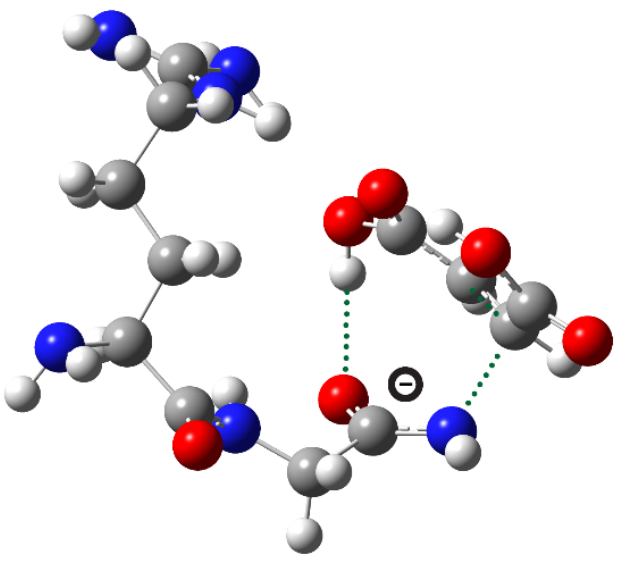

TS_z $\mathbf{z}_{1-} \mathbf{b}$

Figure S8: Key transition structures in the lowest energy pathways to $z_{l}$ anion formation. The pathways are indistinguishable energetically at $298 \mathrm{~K}$ as the rate-limiting $\mathrm{C}-\mathrm{H}$ transfer steps require 256.5 and $256.8 \mathrm{~kJ} \mathrm{~mol}^{-1}$ respectively $\left(\Delta H_{298 \mathrm{~K}}\right)$. TS_z1_a (panel b) follows TS_H+transfer_a (panel a) and TS_z1_b (panel d) follows TS_H+transfer_b (panel c). Approximate positions of the charges in each structure are provided for illustration. Green dotted lines indicate bonds being broken or formed. 

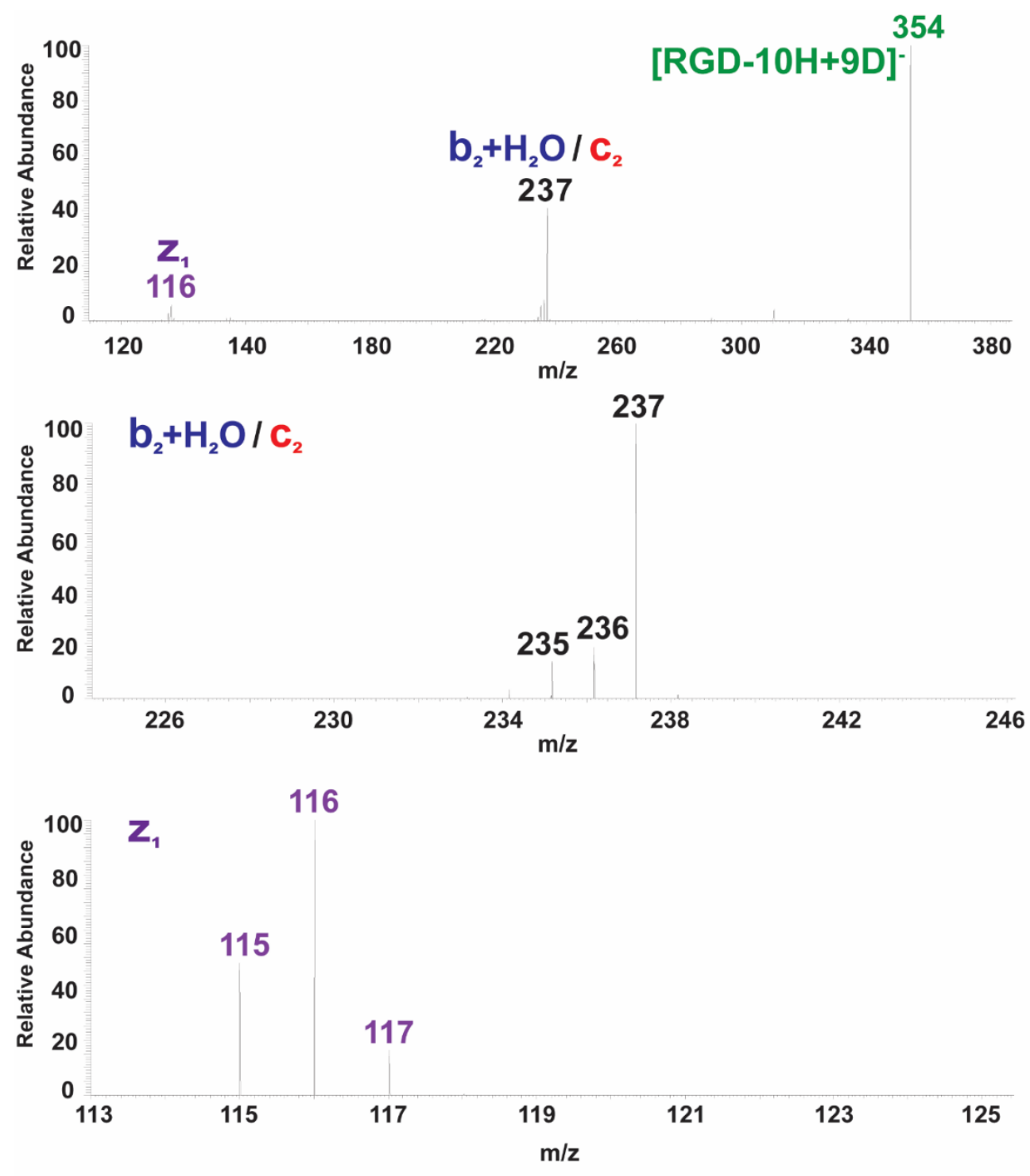

Figure S9: (Top panel) MS/MS spectrum of isolated $\mathrm{m} / z$ 354 \pm 0.5 peak, which is primarily [RGD-10H+9D]', isolated from the peak distribution $(\mathrm{m} / \mathrm{z} 351,352,353,354,355)$ of deprotonated RGD generated from ESI of acetonitrile/ $\mathrm{D}_{2} \mathrm{O}(50 / 50)$ solutions. Collision energy is $15 \mathrm{eV}$ in the laboratory frame. (Middle panel) Zoom-in of the overlapping $b_{2}+\mathrm{H}_{2} \mathrm{O}$ and $c_{2}$ peak distributions. The $b_{2}+\mathrm{H}_{2} \mathrm{O}$ peak has up to 7 facilely exchanged $\mathrm{N}-\mathrm{H}$ to $\mathrm{N}-\mathrm{D}$, protons $(\mathrm{m} / \mathrm{z} 230$ >237). The far less abundant $c_{2}$ anion has up to $8 \mathrm{~N}-\mathrm{H}$ to N-D, protons (m/z 229->237). (Bottom panel) Zoom-in of $z_{1}$ peak distribution indicating mobilization of (and subsequent scrambling of) $\mathrm{C}-\mathrm{H}$ protons consistent with the literature. 

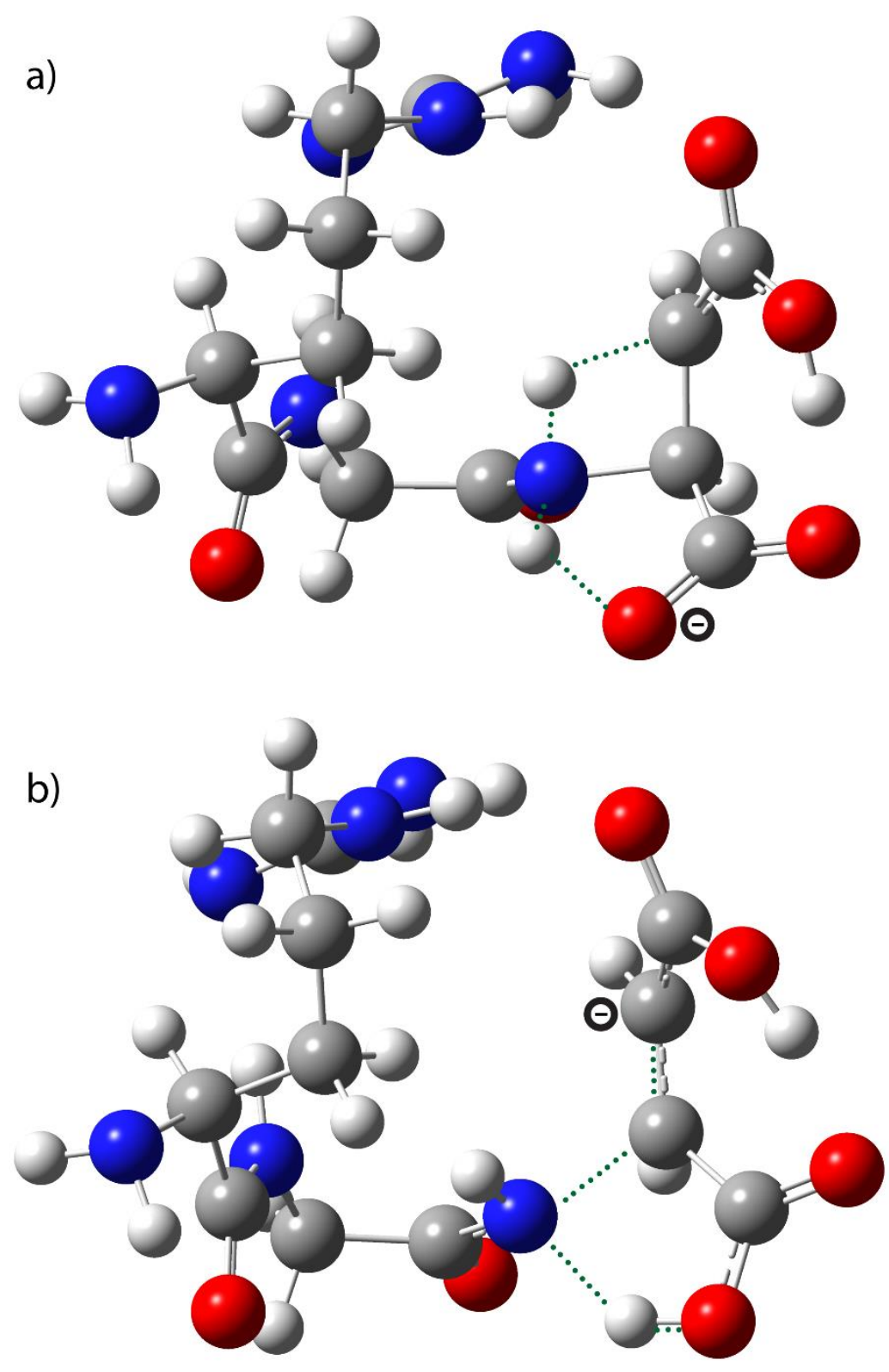

Figure S10: Alternate $c_{2}$ anion formation transition structures: (a) Abstraction of a $\mathrm{C}-\mathrm{H}$ proton from the aspartyl sidechain by the aspartyl nitrogen, TS_H $\mathrm{H}^{+}$transfer_c. (b) Cleavage of the N-C $\mathrm{Clpha}$ bond to form the $z_{1}$ anion, TS_z1_c. Approximate positions of the charges in each structure are provided for illustration. Green dotted lines indicate bonds being broken or formed. 


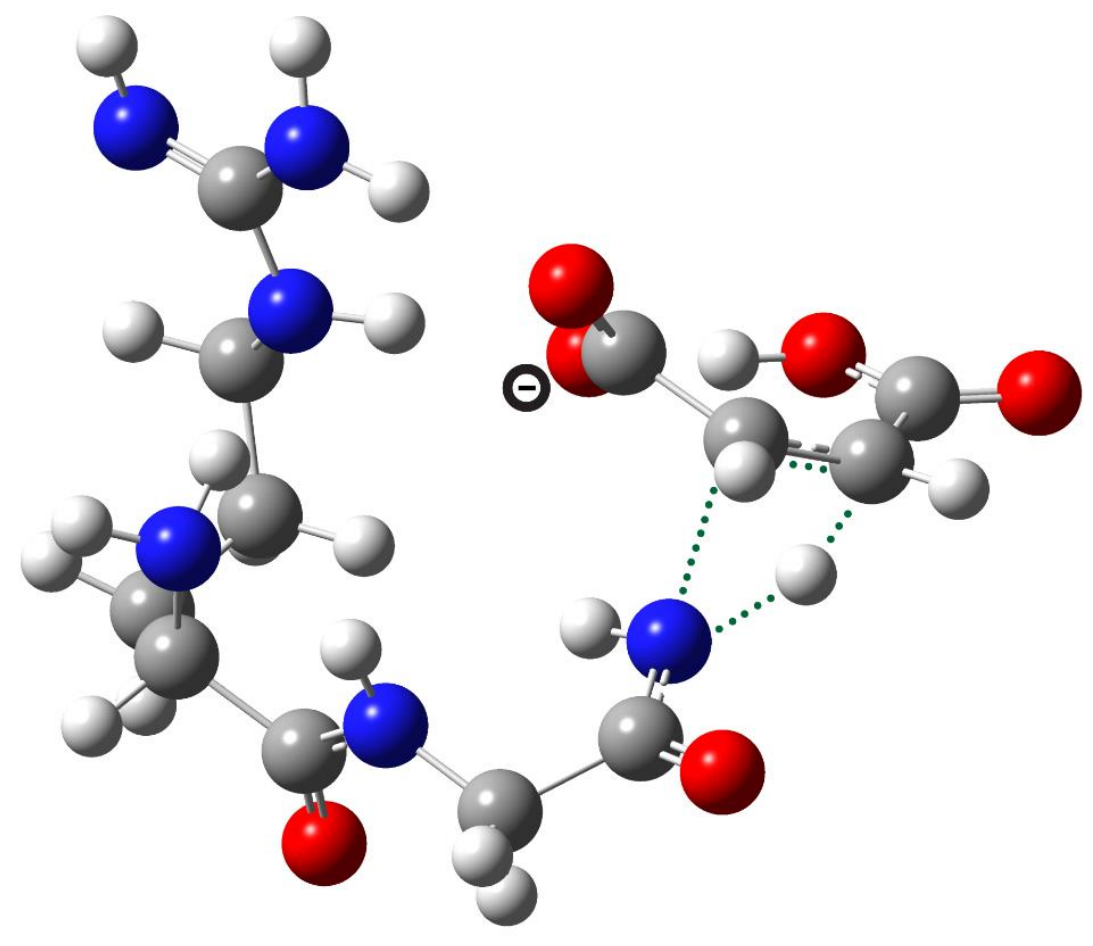

Figure S11: Alternate, higher energy $c_{2}$ anion formation transition structure (TS_z1_d). This enables concerted abstraction of a $\mathrm{C}-\mathrm{H}$ proton from the aspartyl sidechain and cleavage of the $\mathrm{N}-\mathrm{C}_{\text {alpha }}$ bond to form the $z_{1}$ anion. Approximate positions of the charges in each structure are provided for illustration. Green dotted lines indicate bonds being broken or formed. 
<smiles>[R20]O[Na]</smiles><smiles>N=C(N)NCCCC(N)C(=O)NCC(=O)N1CCOC(=O)CC1C(=O)OCCO</smiles>

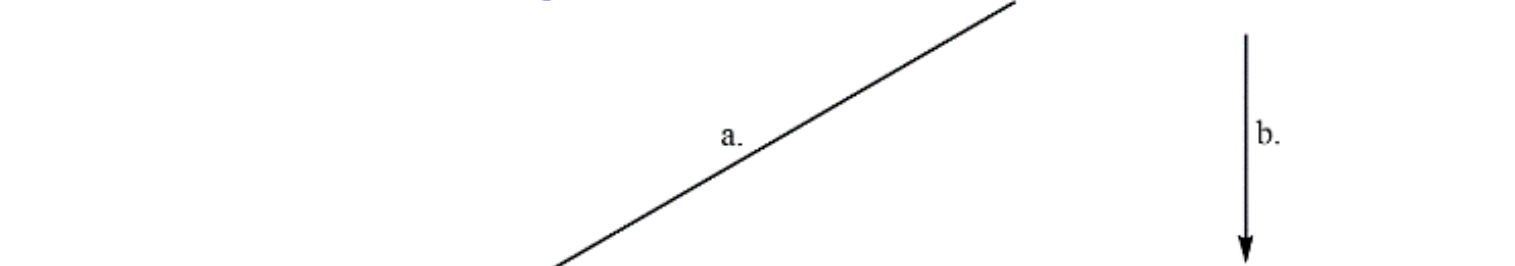

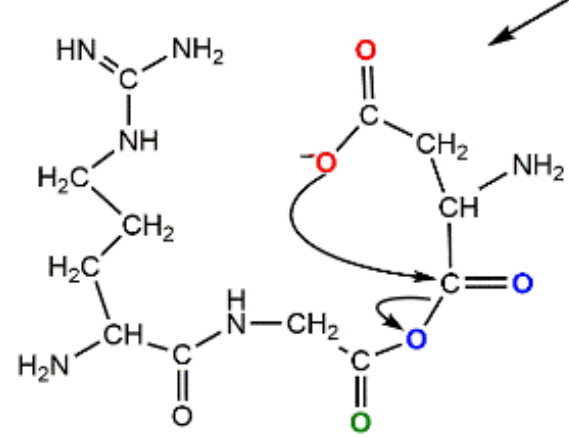<smiles></smiles><smiles>N=C(N)NCCCC(N)C(=O)NCC(=O)[O-]</smiles>

\section{$\mathrm{b}_{2}+\mathrm{H}_{2} \mathrm{O}$ Anion}<smiles>N=C(N)NCCCC(N)C(=O)NCC(=O)O[Na]</smiles>

Scheme S1. Two analogous $b_{2}+H_{2} \mathrm{O}$-forming forming mechanisms with the carboxyls color-coded for ease of viewing. Note that the second structure (zwitterion protonated at the second amide nitrogen) is a fleeting intermediate rather than a stable minimum energy structure according to our calculations. i.e., drawn explicitly, solely for ease of illustration. In practice, pathway $b$ is the least energetically demanding (see main text for specifics). 

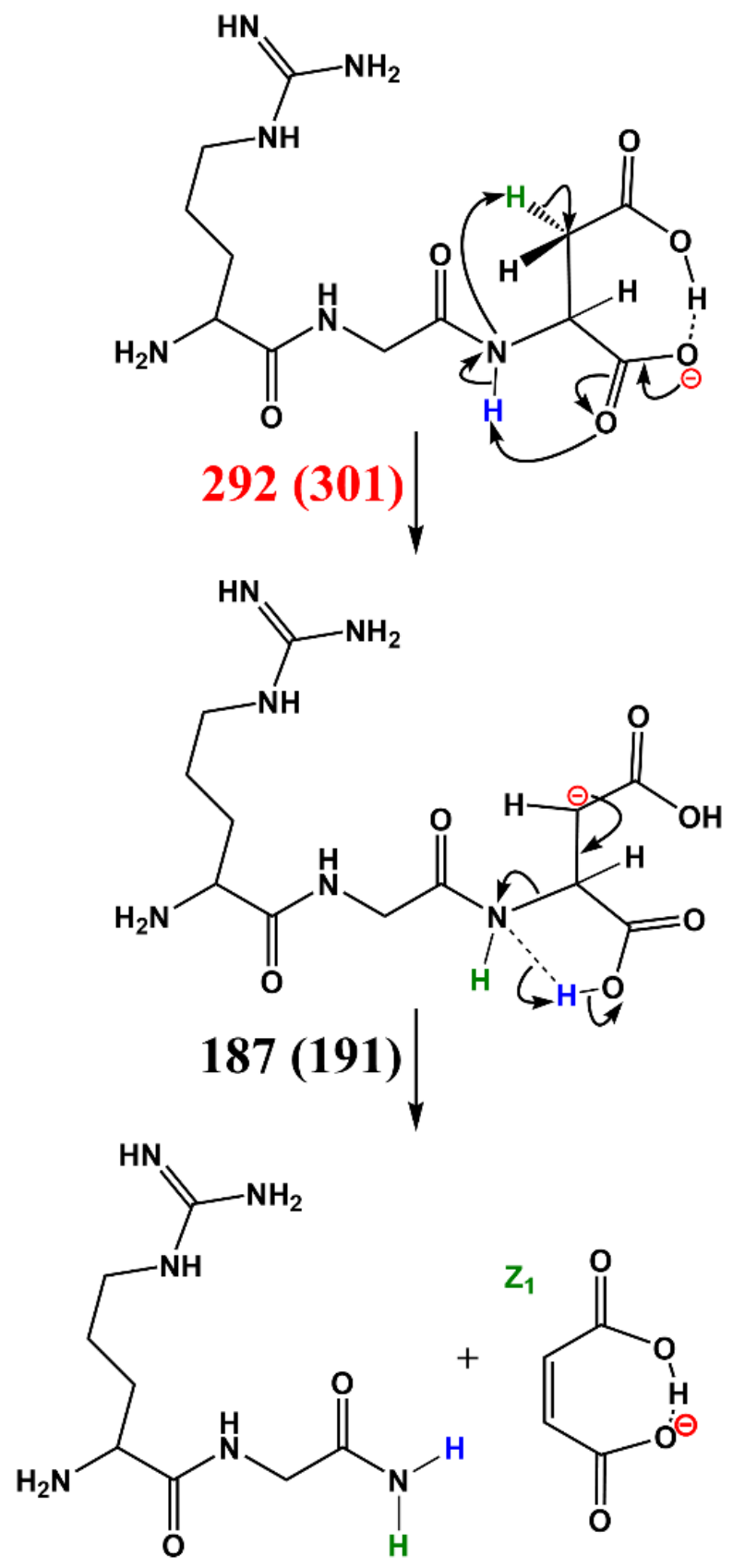

Scheme S2. Multistep reaction pathway for $z_{1}$ anion-formation by mobilization of C-H proton to the aspartic acid amide nitrogen, then cleavage of the $\mathrm{N}-\mathrm{C}_{\text {alpha }}$ bond [RGD-H]- The $\Delta \mathrm{H}_{298 \mathrm{~K}}$ $\left(\Delta \mathrm{G}_{298 \mathrm{~K}}\right)$ barriers are in $\mathrm{kJ} \mathrm{mol}^{-1}$. 

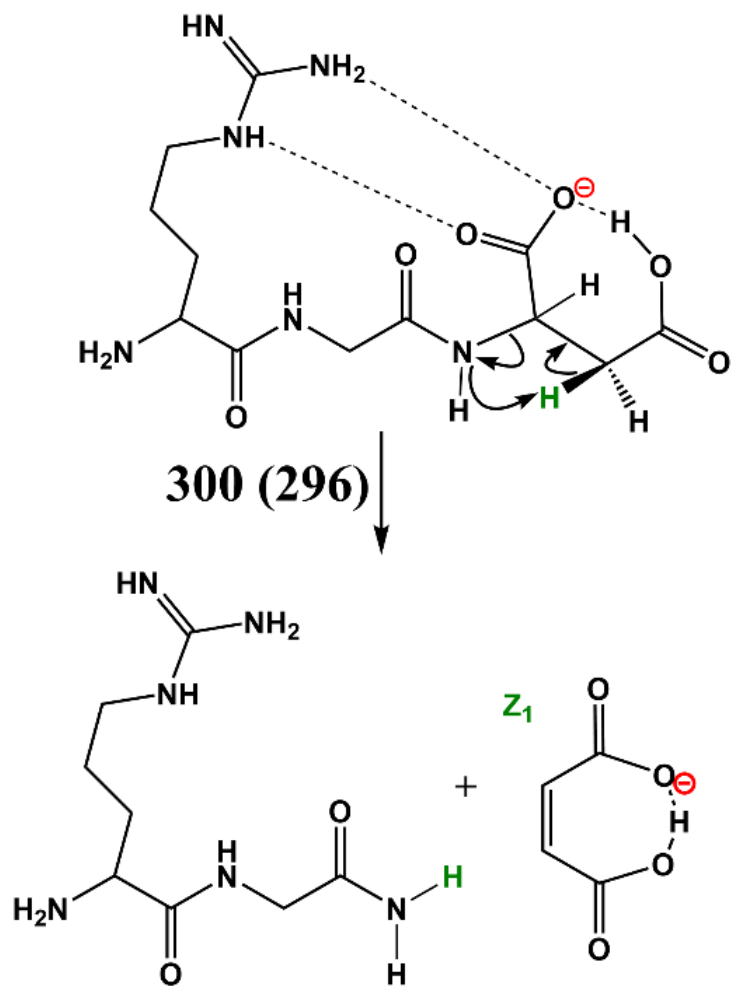

Scheme S3. Single step $\mathrm{C}-\mathrm{H}$ proton transfer and $\mathrm{N}-\mathrm{C}_{\text {alpha }}$ bond cleavage to form a $z_{1}$ anion from [RGD-H] $]^{-}$The $\Delta \mathrm{H}_{298 \mathrm{~K}}\left(\Delta \mathrm{G}_{298 \mathrm{~K}}\right)$ barriers are in $\mathrm{kJ} \mathrm{mol}^{-1}$. 